\title{
Afectación de la calidad de agua de los pozos del campus Tecnológico de Cancún por mancha urbana
}

\author{
Affecting well water quality by population increase, at the Cancún Technology \\ campus
}

TORRES-RIVERO, Ligia Adelayda $\dagger^{*}$

TECNM/ Campus Instituto Tecnologico de Cancun. México.

ID $1^{\text {er }}$ Autor: Ligia Adelayda, Torres-Rivero / ORC ID: 0000-0002-3303-3437, CVU CONACYT ID: 316421

DOI: $10.35429 / J U S D .2020 .19 .6 .1 .13$

Recibido: 05 de Julio, 2020; Aceptado 30 de Diciembre, 2020

\section{Resumen}

Con el fin de desarrollar un diagnóstico de la calidad del agua de pozo, se evaluó la calidad física, química y bacteriológica de las aguas subterráneas, con el propósito de saber cómo afecta al aumento de la población que está circunscribiendo con el IT Cancún. Nuestro primordial objetivo fue determinar índices de calidad del pozo que suministra agua a nuestras instalaciones de nuestra campus tomando en cuenta temporalidad de los años en 20162017,comparando los parámetros físicos del contenido total de sólidos disueltos fueron evaluados, conductividad, $\mathrm{PH}$, dureza, salinidad, químicos, grasas y aceites, biológicos E. Collí y Coliformes totales por el Método Quanty Try Colilert, los resultados indican las concentraciones de los iones analizados, la hidrogeología de la península de Yucatán de tipo cavernoso, con permeabilidad, por el agua residual, la lluvia se produce en un proceso de contaminación antropogénica, los componentes analizados físicos dieron un alto valor a los límites máximos permisibles de acuerdo con NOM-127-SSA1-1994 modificado 2000, Sólidos suspendidos $1200 \mathrm{mg} / \mathrm{L}$, dureza 950 ppm, grasas y aceites $65 \mathrm{mg} / \mathrm{l}$, E. Coli se utilizó el método de E. Colilert the Colilert Quanty para determinar el número más probable de bacterias el resultado de la muestra nos arroja >2419.6 NPM un alto contenido de contaminación fecal.

Agua de pozos, Contaminación, Mancha urbana

\begin{abstract}
In order to develop a diagnosis of well water quality, the physical, chemical and bacteriological quality of groundwater was evaluated, with the aim of knowing how it affects the increase in the population that is limited by IT cancún Our primary objective was to determine quality indices of the well that supplies water to our campus facilities taking into account the temporality of the years in 2016-2017, comparing the physical parameters of the total content of dissolved solids were evaluated, conductivity, $\mathrm{pH}$, hardness, salinity, chemicals, fats and oils, biological $\mathrm{E}$ Collí y Coliformes totales por el Método Quanty Try Colilert, los resultados indican las concentraciones de los iones analizados, la hidrogeología de la península de Yucatán de tipo cavernoso, con permeabilidad, por el agua residual, la lluvia se produce en un proceso de contaminación antropogénica, the physical components analysed gave a high value to the maximum permissible limits according to NOM-127-SSA1-1994 modified 2000, Suspended solids $1200 \mathrm{mg} / \mathrm{L}$, hardness $950 \mathrm{ppm}$, fats and oils $65 \mathrm{mg} / \mathrm{l}$, E. Coli was used the method of E. Colilert the Colilert Quanty to determine the most likely number of bacteria the result of the sample gives us >2419.6 NPM a high content of faecal contamination.
\end{abstract}

Well water, Pollution, Urban spot

Citación: TORRES-RIVERO, Ligia Adelayda. Afectación de la calidad de agua de los pozos del campus Tecnológico de Cancún por mancha urbana. Revista del Desarrollo Urbano y Sustentable. 2020. 6-19:1-13.

*Correspondencia al autor (Correo electrónico: ligia.tr@cancun.tecnm.mx)

$\dagger$ Investigador contribuyendo como primer autor 


\section{Introducción}

Las principales amenazas para el acuífero se derivan del manejo inadecuado de los desechos generados por la actividad antropomórfica y comercial, y por consecuencia del crecimiento poblacional, manifestado en el incremento de la zona en los últimos años en Cancún, Quintana ROO.

La Península de Yucatán es una región conformada por rocas calcáreas y carece de corrientes superficiales debido a la karstificación extensa zonas con presencia de calizas y yesos, la cual da lugar a fracturas y fisuras por donde se filtra rápidamente el agua de lluvia disolviendo y arrastrando los contaminantes que encuentra a su paso. La baja profundidad de los niveles freáticos y la falta de suelo hacen que los solutos se infiltren al agua subterránea, haciéndola vulnerable a la contaminación, los pozos, los cenotes, humedales.

La calidad del agua está siendo afectados por las actividades antropogénicas que se desarrollan en las zonas habitacionales, gasolinerías, restaurants, así como escuelas, lavaderos de autos podrían ser los generadores de mayores afectaciones, nuestro instituto quedo inserto dentro de una gran mancha urbana, así como terrenos baldíos, se indica en la Figura 1 donde está posicionado, y sus colindancias.

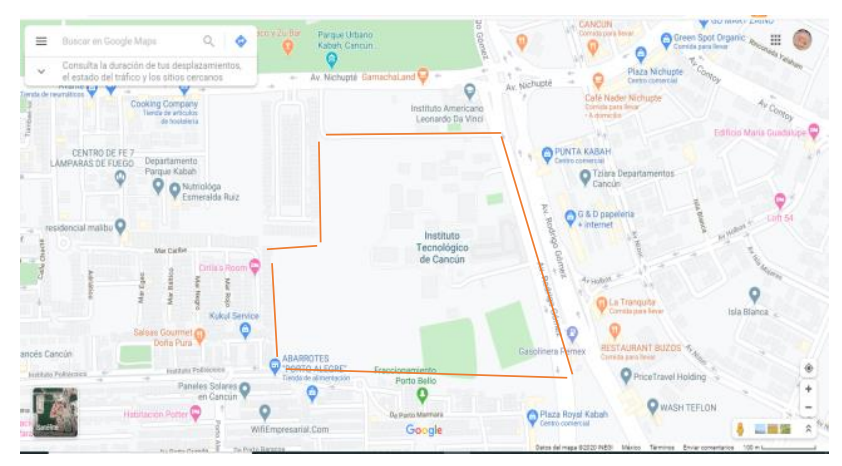

Figura 1 Ubicación del IT Cancún

Fuente: Google maps

Quedando el IT Cancún rodeado de fraccionamientos, ubicado en una de las avenidas más importantes del municipio, esto no llevo al estudio de conocer la calidad del agua de pozo, que abastece a 2 cisternas, bombeando agua para los baños y al sistema de riego, y servicio de las cafeterías.
En los últimos 25 años, las temperaturas máxima y mínima promedio han sido de $33.4^{\circ} \mathrm{C}$ y $24.2{ }^{\circ} \mathrm{C}$ respectivamente. Sin embargo, durante estos mismos años se han expuesto temperaturas muy por altas, alcanzando valores extremos de hasta $41.5^{\circ} \mathrm{C}$ de máxima y $9.5^{\circ} \mathrm{C}$ de mínima. en los años 2016-2017 se observa que los meses que registran la mayor oscilación térmica son abril y mayo, cuando empieza el calor, y va en aumento de 1.1 grado debido a los efectos generados por el cambio climático, septiembre, diciembre se registran los valores más bajos de oscilación térmica, siendo los meses de mayor precipitación para la ciudad de Cancún.

En 2016 fue el año más cálido del que se tenga constancia: registró una temperatura sorprendente de $1.1^{\circ} \mathrm{C}$ por encima de los niveles preindustriales, lo que representa un aumento de $0.06{ }^{\circ} \mathrm{C}$ por encima del récord anterior registrado en 2015. Este ascenso de la temperatura mundial está en consonancia con otros cambios que se están produciendo en el sistema climático", afirmó Petteri Taalas, Secretario General de la OMM.

Debido al excelso crecimiento de la población de esta ciudad; para 1976 había en Cancún 15 mil habitantes, 10 años después la cifra había aumentado a 100 mil habitantes. Posteriormente se presenta una disminución en el creciendo, en el año de 1996 alcanza los 324 mil habitantes debido al engrandecimiento de la actividad Turística. En el año 2010 la población era de 628,306 habitantes (INEGI, 2010a), la cifra ha aumento casi en un $50 \%$, en la expectativa que alcance el millón para el 2030, (Anuario estadístico y geográfico de Quintana Roo 2016).

\section{Calidad del agua}

La calidad del agua es uno de los temas más importantes en la gestión de los recursos hídricos como lo revela (Sutadian et al., 2016), según comenta Medeiros et al., 2017 categorización establecida en el que la calidad del agua y contaminación data de 1848 y se evalúa desde las características físicas, químicas y bilógicas. 
Para el índice de calidad del agua (ICA) es una de las herramientas más seguras para indicar la calidad de aguas subterráneas, al evaluar los parámetros fisicoquímicos y microbiológicos relacionados con el nivel de riesgo sanitario destinado al consumo humano. Avvannavar y Shirihari (2008).

La calidad del agua se considera un criterio, el cual depende del uso que se le dé al líquido, por lo que cada uso requiere un determinado estándar de calidad. Los estudios de la calidad fisicoquímicos y microbiológicos de las fuentes de agua destinadas a consumo humano constituyen un requisito necesario e indispensable para evaluar su aptitud para este uso, que sin duda es el más delicado del recurso. Un mecanismo difundido para esta tarea constituye los índices de calidad, que resumen una gran cantidad de información, hasta obtener un número que le ubica al agua en una determinada categoría. Cuando la fuente a evaluar está sujeta a variaciones meteorológicas como los ríos, es necesario que el diagnóstico incluya un período representativo de evaluación que permita detectar las variaciones temporales y espaciales a la que están sujetas.

\section{Indicadores de calidad del agua}

A principios de los años setenta, ante la necesidad de encontrar un método uniforme y consistente para dar a conocer la calidad del agua de manera accesible a la población, se desarrolló un sistema estimativo de calidad del agua que requirió la medición física de los parámetros de contaminación del agua y el uso de una escala estandarizada de medición para expresar la relación entre la existencia de varios contaminantes en el agua y el grado de impacto en los diferentes usos de esta

Éste índice consideró 18 parámetros para su cálculo con distintos pesos relativos (Wi), según la importancia que se le concedía a cada uno de ellos en la evaluación total, como se indica en la Tabla 1. Este sistema se denominó Índice de Calidad del Agua (ICA) y permitía hacer comparaciones de niveles de contaminación en diferentes áreas. El ICA se define como el grado de contaminación existente en el agua a la fecha de un muestreo, expresado como un porcentaje de agua pura. Así, agua altamente contaminada tendrá un ICA cercano o igual a $0 \%$ y de $100 \%$ para el agua en excelentes condiciones.

\begin{tabular}{|l|l|}
\hline \multicolumn{1}{|c|}{$\begin{array}{c}\text { Demanda Bioquímica de } \\
\text { Oxígeno }\end{array}$} & \multicolumn{1}{c|}{$\begin{array}{c}\text { Nitrógeno en } \\
\text { nitratos }\end{array}$} \\
\hline Oxígeno disuelto & Alcalinidad \\
\hline Coliformes fecales & Color \\
\hline Coliformes totales ar azul de & $\begin{array}{l}\text { Potencial total de } \\
\text { Hidrógeno (pH) }\end{array}$ \\
\hline $\begin{array}{l}\text { Sustancias activas al } \\
\text { metileno (Detergentes) }\end{array}$ & $\begin{array}{l}\text { Sólidos } \\
\text { suspendidos }\end{array}$ \\
\hline Conductividad eléctrica & Cloruros \\
\hline Fosfatos totales & Sólidos disueltos \\
\hline Grasas y aceites & Turbiedad \\
\hline Nitrógeno amoniacal & \\
\hline
\end{tabular}

Tabla 1 Parámetros que determinan la calidad de agua Fuente: SEMARNAT Gerencia de calidad del Agua, Junio, 2019

\section{Contaminación del agua}

Las necesidades de agua exceden por mucho la disponibilidad en cuanto a cantidad y calidad de estas, la problemática en los municipios de Quintana ROO son la a disposición aguas grises, ya que en la mayoría de los casos son vertidas sin un tratamiento previo a los cuerpos de agua superficiales, pozos, en algunas zonas utilizan fosas sépticas. Se continua realizando el fecalismo al aire libre en la actualidad realizando el fecalismo a cielo abierto, contaminando así el acuífero por la alta permeabilidad del subsuelo.

El problema del agua subterránea es debido diversas actividades económicas como son lavaderos de autos, escuelas, plazas comerciales vierten sus productos orgánicos, inorgánicos por lixiviación se filtran dichos contaminantes hacia los cuerpos de agua subterránea. La urbanización es una fuente de contaminación de agua del subsuelo, manto freático, por ejemplo, derrames de gasolina, mala disposición de los aceites comestibles usados. El agua subterránea en temporada de sequias juega un papel importante en el abastecimiento en el suministro del agua potable, cambio climático genera un impacto al aumento de las actividades humanas causando una baja fundamental en la recarga de agua subterránea, así como la degradación de la misma asociada a los ecosistemas a la mala disposición de los diferentes tipos de residuos desde orgánicos e inorgánicos. Para ArboledaBaena, C M. et al., 2016 los métodos para la detección de microorganismos patógenos de origen intestinal en el agua en general son de alto costo e implican largos tiempos para su determinación, en comparación con los Coliformes totales y Escherichia coli. 
Estos microrganismos se constituyen en excelentes indicadores de contaminación, al hacer la correspondencia con la presencia de otros patógenos de vías intestinales. Determinar la presencia de estos indicadores en el agua permitirá indicar la calidad microbiológica del cuerpo de agua.

\section{Contaminación microbiológica del agua}

La definimos como la introducción de agentes biológicos al agua, los cuales sobrellevan a una alteración no deseable de la composición natural de los cuerpos de agua. Haciéndola no apta para el consumo humano

\section{Evidentemente Chambi Choque} considera que las enfermedades infecciosas que son causadas por organismos patógenos como las bacterias, virus y parásitos, son un riesgo más común para la salud que está asociado al consumo de agua.La contaminación del agua subterránea por percolación de lixiviados fruto de actividades antropogénicas como la disposición final de aguas residuales, el mal diseño, los cuales se sitúan en algunos casos en un contexto geológicamente inadecuado, las actividades domésticas, entre otros, constituyen uno de los mayores problemas ambientales en todo el entorno, ya que el volumen de contaminación generada es directamente proporcional al grado del crecimiento de la población

\section{Tipos de contaminación que afectan los cuerpos de agua}

Contaminación Química: se conoce como a la variedad de productos químicos como productos industriales, detergentes, aceites disolventes, pesticidas, herbicidas y combustible se pueden acumular en el agua (Calvo, 2016).

Contaminación Microbiológica: se denomina a la cantidad de microorganismo patógeno (bacterias, virus y protozoos) pueden contaminar el agua. El mal estado del agua en sus parámetros trae enfermedades como la colera y otros. Cajas Condezo, M. A. (2020).
Contaminantes que consumen oxígeno: exceso de materiales biodegradables

Microorganismos que determinan la calidad de agua

Los estándares internacionales indicadores de la calidad del agua potable, importantes para su valoración de riesgo sanitario (EPA United States Environmental Protection Agency, 2011). Los clasifica en Bacterias Coliformes totales, Escherichia coli, Bacterias coliformes, los virus, los protozoarios, los helmintos.

\section{Legislación}

Con respecto a las Normas Oficiales Mexicanas relacionadas con el agua, las que se encuentran vigentes y son aplicables para las condiciones del pozo de agua IT Cancún.

Los parámetros de la calidad del agua en aspectos químicos, físicos y biológicos, metodológicos; en México se utiliza la NOM127-SSA1-2000, en el uso del agua para consumo humano, se evalúa del estado físico y químico, biológicos del agua.

De acuerdo con la Norma Oficial Mexicana NOM-127-SSA1-1994 (modificada), "Salud ambiental, agua para uso y consumo humano límites permisibles de calidad $\mathrm{y}$ tratamiento a que debe someterse el agua para su potabilización" (NOM-127, 2000) que el agua para consumo humano con calidad adecuada es fundamental, para prevenir y evitar transmisión de enfermedades gastrointestinales y otras; para lo cual, a establecidos límites permisibles en cuanto a sus características bacteriológicas, físicas, organolépticas y químicas, en relación a los parámetros de las muestras que se obtuvieron.

Los resultados de los análisis bacteriológicos se reportan en unidades de NMP/100 ml (número más probable por 100 $\mathrm{ml}$ ), si se utiliza la técnica del número más probable o UFC/100 ml (unidades formadoras de colonias por $100 \mathrm{ml}$ ), si se utiliza la técnica de filtración por membrana, límites permisibles como se reportan igualmente cuando se utiliza la técnica de Colilert Quanty Try 2000, en la tabla 2, anexos se indican los límites máximos permisibles, para cada parámetro. 


\section{Descripción del método}

Lugar de muestreo pozo de abastecimiento del IT Cancún, se muestreo 2 veces por año, debido a la temporalidad de las ondas de alta temperatura y temporada la lluvia, temporada de seca y de aumento en la precipitación pluvial se recolectó un volumen de 2 litros en recipientes de plástico, como lo indica la NOM230-SSA1-2000 como se indica en la figura 2. Para a ser un comparativo del grado de contaminación del agua por escorrentía, infiltraciones de algún contaminante en mayor concentración en una época y otra, y de un año a otro. Véase tabla 3.

El año 2016 hizo historia con una temperatura máxima mundial sin precedentes, un nivel excepcionalmente bajo de los hielos marinos y un aumento ininterrumpido del nivel del mar y del calor oceánico, de acuerdo con la Organización Meteorológica Mundial (OMM). Las condiciones meteorológicas y climáticas extremas no han cesado en 2017.

\begin{tabular}{|l|r|r|r|r|}
\hline \multicolumn{1}{|c|}{ Temporalidad } & Secas & \multicolumn{1}{c|}{ Lluvias } & \multicolumn{1}{c|}{ Secas } & \multicolumn{1}{c|}{ Lluvias } \\
\hline Mes del muestreo & Mayo & Octubre & Mayo & Octubre \\
\hline Temperaturas & $30-37$ & $24-29$ & $30-38$ & $24-29$ \\
\hline
\end{tabular}

Tabla 2 Temporalidad para el muestreo condiciones del clima año 2016 fue un año con muchas variantes con respecto a la cantidad de lluvia 2017 los efectos del niño Fuente: Elaboración propia

\section{Parámetros físicos}

Para la determinación de los parámetros físicos como son $\mathrm{pH}$, conductividad, turbiedad de se utilizó una sonda multiparamétrica de la marca Xplorer GLX.

Se configura el equipo para una correcta lectura, calibrar las diferentes sondas multiparamétricas del equipo. Se toman $2 \mathrm{~mL}$ de la muestra o $100 \mathrm{~mL}$ dependiendo se la sonda las lecturas se hicieron in situ.

\section{Parámetros químicos}

La dureza total como $\mathrm{CaCO}_{3}$ se analizaron por métodos volumétricos, de acuerdo con la NMXAA-072-SCFI-2001.
Dureza el cual como se coloca en la bureta con una solución de EDTA a $0.01 \mathrm{M}$, se toma $20 \mathrm{~mL}$ de nuestra muestra y se le agrego $100 \mathrm{~mL}$ de agua destilada. Posteriormente se le añadió una solución para elevar el pH a 10 para proceder hacer la titulación. Para esto fue necesario agregar negro de eriocromo y titulo hasta que el vire a azul.

Las aguas domésticas como a las industriales y desde la ósmosis inversa que es uno de los principales parámetros que se deben controlar.

Las aguas que contienen menos de 50 ppm de $\mathrm{CO}_{3} \mathrm{Ca}$ se llaman blandas, $100 \mathrm{ppm}$ de $\mathrm{CO}_{3} \mathrm{Ca}$, ligeramente duras $200 \mathrm{ppm}$ de $\mathrm{CO} 3 \mathrm{Ca}$, moderadamente duras., $500 \mathrm{ppm}$ de $\mathrm{CO}_{3} \mathrm{Ca}$, muy duras produciendo grandes cantidades de costras en las tuberías, como es el caso en la península de Yucatán que tiene aguas duras por ser conformación de tipo calcárea.

El agua blanda, cuya dureza es inferior a $100 \mathrm{mg} / \mathrm{L}$, puede tener una capacidad reducida y resultar, por tanto, más corrosiva para las tuberías, por lo que ciertos metales pesados como el cobre, zinc, plomo y cadmio pueden estar presentes en el agua potable. El grado de corrosión y solubilización de los metales también depende del $\mathrm{pH}$, la alcalinidad y de la concentración de oxígeno disuelto, APHA, AWWA, WPCF, 1998.

la dureza y la alcalinidad, para el cálculo del $\mathrm{pH}$ de saturación se tiene en cuenta la concentración de sólidos totales disueltos, así como también la temperatura.

\section{Alcalinidad NMX-AA-036-SCFI-2001}

La determinación de alcalinidad se utiliza fenolftaleína como indicador con $25 \mathrm{ml}$ de $\mathrm{H}_{2 \mathrm{SO}_{4}}$ a $0.02 \mathrm{~N}$. Se toma $100 \mathrm{ml}$ de la muestra. Se le agregan 3 gotas de fenolftaleína se agita hasta el cambio de color por titilación, para la determinación de alcalinidad se le añadió 2 gotas de indicador metil naranja, seguir titulando hasta cambio de color al naranja. 


\section{Grasas y aceites NMX-AA-005-SCFI-201}

En la medición de grasas y aceites no se mide una sustancia específica, sino un grupo de sustancias con unas mismas características fisicoquímicas (solubilidad). (NMX-AA-005SCFI-2013)

Preparar los matraces de extracción introduciéndolos al horno a una temperatura de $103{ }^{\circ} \mathrm{C} \pm 2{ }^{\circ} \mathrm{C}$, enfriar en desecador y pesarlos, repetir el procedimiento hasta obtener una diferencia de $<0.0005$ g. Preparar el material filtrante colocando un papel filtro en el embudo Büchner, colocar el embudo en un matraz Kitazato y agregar $100 \mathrm{~mL}$ de la suspensión de tierra de diatomeas-sílice sobre el filtro, aplicar vacío y lavar con al menos $100 \mathrm{~mL}$ de agua. Para el volumen inicial de la muestra es de 100 $\mathrm{ml}$ vierta el filtrado en una probeta de $1 \mathrm{~L}$.

Preparar el equipo de extracción, con la muestra en el dedal de celulosa, del reflujo y extraer a una velocidad de 20 ciclos/hora durante un período de $4 \mathrm{H}$.

Calcular las grasas y aceites recuperables (GYA) en la muestra usando la siguiente ecuación:

$\mathrm{GYA}=\left(\frac{(M f-M i)}{V}-\right.$ Blanco

$\mathrm{Mf}=$ peso final de la muestra

Volumen de la muestra

$\mathrm{Mi}=$ peso inicial de la muestra

\section{Determinación de solido disueltos totales NMX-AA-034-SCFI-2015}

La determinación de solido disueltos totales nos basamos en la NMX-AA-034-SCFI-2015. Es el material soluble constituido por materia inorgánica y orgánica que permanece como residuo después de evaporar y secar una muestra previamente filtrada a través de un filtro de fibra de vidrio con poro de $1,5 \mu \mathrm{m}$ a una temperatura de $105^{\circ} \mathrm{C} \pm 2{ }^{\circ} \mathrm{C}$.

Calcular el contenido de sólidos disueltos totales (SDT) de las muestras como sigue:

$$
\mathrm{SDT}=\left(\frac{\mathrm{m} 2-\mathrm{m} 1}{V}\right) \times 1000000
$$

Donde:

$\mathrm{m}_{1}=$ Es la masa de la cápsula vacía, en g.

$\mathrm{m}_{5}$ es la masa de cápsula con el residuo seco de la muestra filtrada, en $\mathrm{g}$.

$\mathrm{V}$ es el volumen de muestra, en $\mathrm{mL}$.

\section{Parámetros biológicos}

Método COLILERT Quanty Try 2000 para la determinación y cuantificación de coliformes totales y Escherichia coli.

Para el parámetro biológico se manejaron frascos muestreadores estériles para posteriormente vaciar a los frascos de $100 \mathrm{ml}$ con conservador de tiosulfato de sodio para hacer la mezcla con el vial disolverlo bien por agitación y vaciarlo a la charola para posteriormente colocarlo en la selladora y sellar, para colocarlo en la incubadora por 24 horas y posteriormente checar el crecimiento o presencia de bacterias E. Coli, por el método Colilert Quanti Try/2000, ver figura 2.

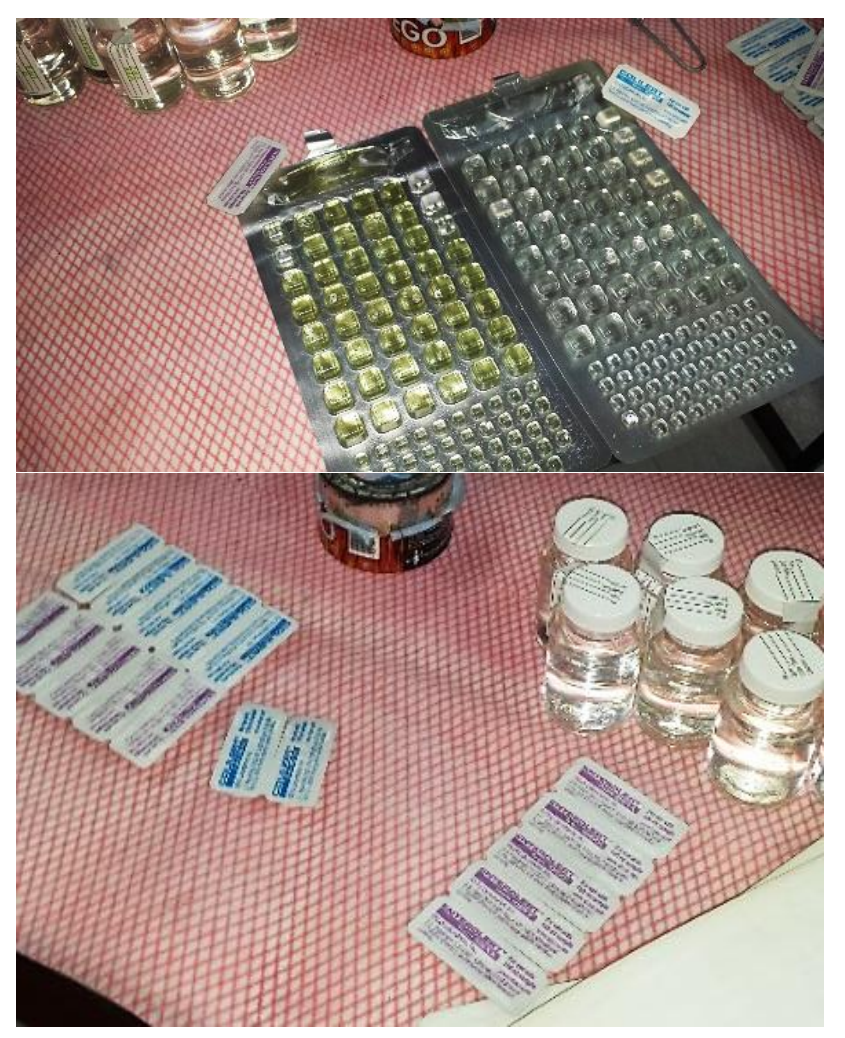

Figura 2 Charolas con las muestras del pozo de agua, sustratos para mezclar con la muestra, la de coloración amarilla es para identificar entero coli, y la transparente coliforme

Fuente: Elaboración propia

TORRES-RIVERO, Ligia Adelayda. Afectación de la calidad de agua de los pozos del campus Tecnológico de Cancún por mancha urbana. Revista del Desarrollo Urbano y Sustentable. 2020 
Se añadió el contenido de una ampolla Colilert. se agitó diez veces el recipiente hasta disolver. Se vertió el contenido del recipiente en la charola previamente identificada QuantiTray/2000, se eliminaron las burbujas y se selló en la IDEXX Quanti-Tray Sealer. Las charolas se incubaron a $35 \pm 1{ }^{\circ} \mathrm{C}$ durante 18 a 24 horas.

Durante todo el ensayo se garantizó la esterilidad siguiendo los lineamientos establecidos en la Norma NMX-AA-102-SCFI2006.

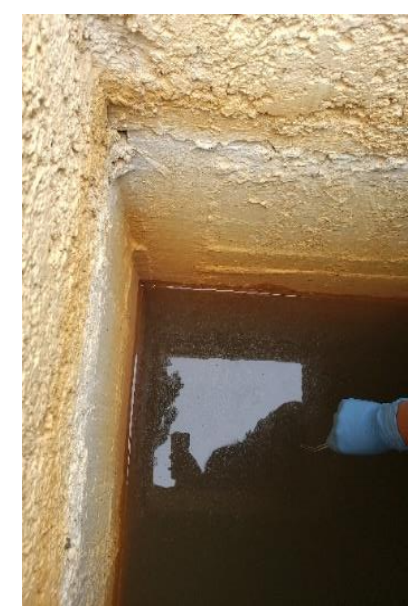

Figura 3 Toma de muestra del brocal del pozo IT Cancun

Fuente: Elaboración propia

Para el análisis del parámetro biológico se esterilizo la zona de muestreo de acuerdo con el procedimiento técnico determinación cualitativa y cuantitativa de coliformes totales y escherichia coli en aguas sustrato definido (Colilert) AOAC 991.15-1994. El pozo muestreado como se indica en la figura 3, tiene aproximadamente niveles estáticos de entre menos de $10 \mathrm{~m}$ de profundidad.

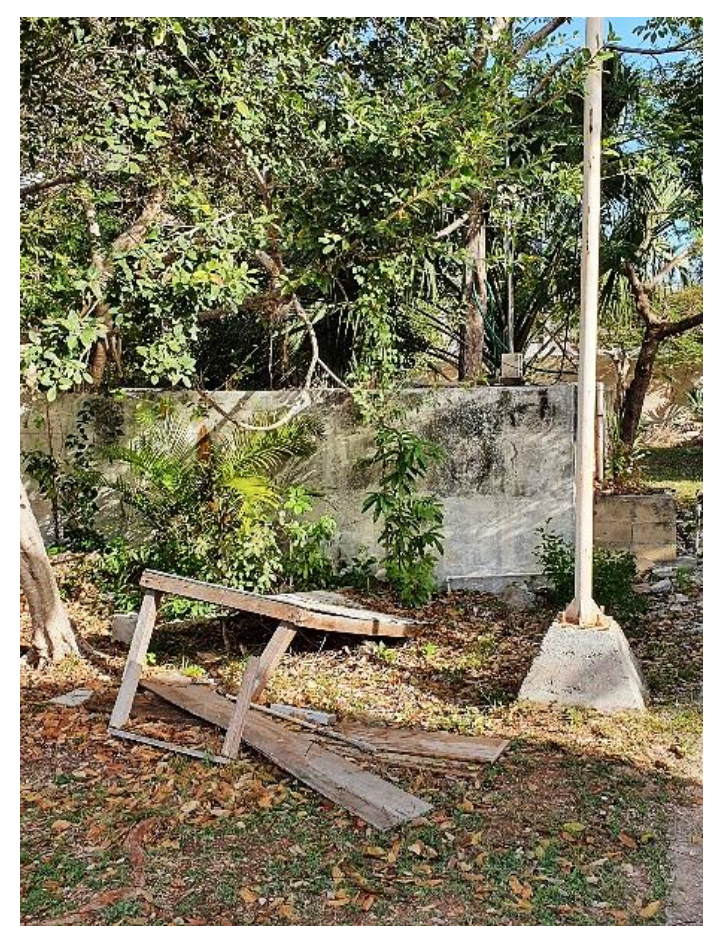

Figura 4 Ubicación de Pozo de abastecimiento de agua, se encuentra cubierto por vegetación de nativa de la zona del IT Cancún

Fuente: Elaboración propia

El muestreo se realizó en los meses de mayo y octubre en ambos años, en los meses de estiaje secas, quemas es en periodo mayo a agosto, 36 y $38^{\circ} \mathrm{C}$, y mínimas entre 10 y $12{ }^{\circ} \mathrm{C}$ los meses septiembre a noviembre, es la temporada de lluvias, huracanes, y aumenta el volumen de agua por lluvias.

\section{Procedimiento}

Para la preservación y muestro de las muestras se llevó a cabo de acuerdo con las siguientes condiciones, véase tabla no 4 , en el apartado de los anexos.

\section{Resultados}

Los resultados obtenidos de los parámetros biológicos se realizaron en base a la compasión de color; Incoloro = negativo, Amarillo = coliformes totales, Amarillo/fluorescente $=E$. coli, con la Tabla IDEXX Quanti-Tray/2000 Véase figura 5. Escherichia coli contando el número de pozos grandes y pequeños que presentan color Amarillo y Fluorescencia al exponer la Bandeja a la luz UV de 365nm en la cabina para lectura de UV pasar el dato a la tabla de NMP (véase tabla 6) interpolar los 2 números (pozos grandes versus pozos pequeños) y obtener el numero coincidente a estos que indica el número de microrganismos en $100 \mathrm{ml}$ véase tabla 5 en el anexo.

TORRES-RIVERO, Ligia Adelayda. Afectación de la calidad de agua de los pozos del campus Tecnológico de Cancún por mancha urbana. Revista del Desarrollo Urbano y Sustentable. 2020 
Reportar: $E$. coli $=\quad \mathrm{X}$ microrganismos en $100 \mathrm{ml}$ : (X = Numero hallado en la Tabla

Se realizaron lecturas preliminares entre las 18 y 22 horas de incubación y una lectura final entre las 24 y 28 horas para confirmar para proceder hacer la lectura y el conteo de numero de pozos grandes y pocillos y el grande por cambio de coloración al pasar sobre la charola la lampara de luz UV, generando una fluorescencia aquellos pozos que dieran positivos, se marcaban en la tabla IDEXX como se indica en la tabla 7 que se encuentra en la parte de los anexos. se obtuvo los siguientes resultados como se observan en las figuras 6 y 7 de los meses de muestreo mayo y octubre 2016 , en la temporada de sequía, el resultado $>2419.6$ NPM 100mL de CF, quedando fuera de los parámetros máximos permisibles como lo indica la norma NOM-001-SEMARNAT-2017., véase tabla 3 .

\begin{tabular}{|c|c|c|}
\hline Parámetros & Unidades & $\begin{array}{c}\text { Límite } \\
\text { máximo } \\
\text { permisible }\end{array}$ \\
\hline Gardia lambia & Quiste/L & $0 / 20 \mathrm{~L}$ \\
\hline $\begin{array}{l}\text { Coliformes } \\
\text { fecales o } E \text {. coli }\end{array}$ & $\begin{array}{ll}\text { NMP/100ml } & \text { o } \\
\text { UFC7100ml }\end{array}$ & Ausente \\
\hline Microcistina-LR & $\mathrm{Mg} / \mathrm{L}$ & 1 \\
\hline
\end{tabular}

Tabla 3 Límites máximos permisibles en indicadores biológicos

De acuerdo con la NOM-001SEMARNAT-2017 (modificada) la determinación de coliformes fecales en la descarga será reemplazada por la determinación de Escherichia coli. Se trata de un cambio menor, ya que es el mismo método de análisis indicándose como coliformes fecales.

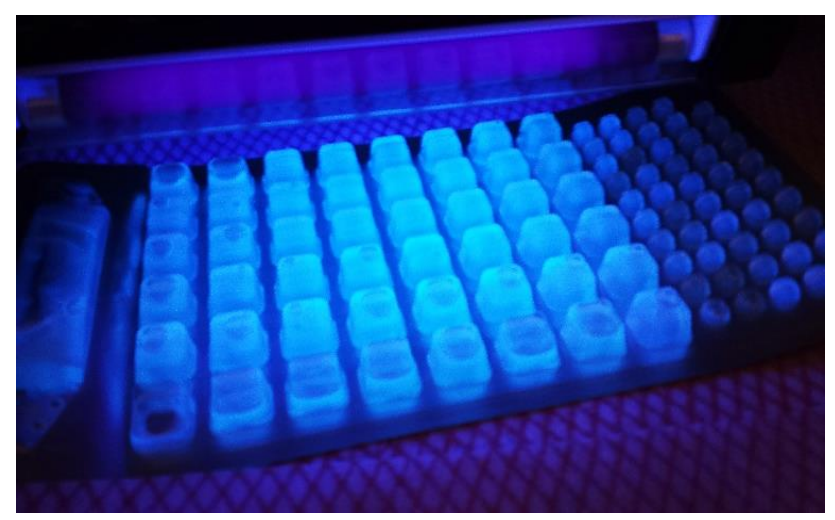

Figura 5 Resultados de la muestra de agua mayo 2016 y octubre 2016-2017, Entero coli, al pasar la lampara de uv en un cuarto obscuro hay presencia de fluorescencia Fuente: Elaboración propia

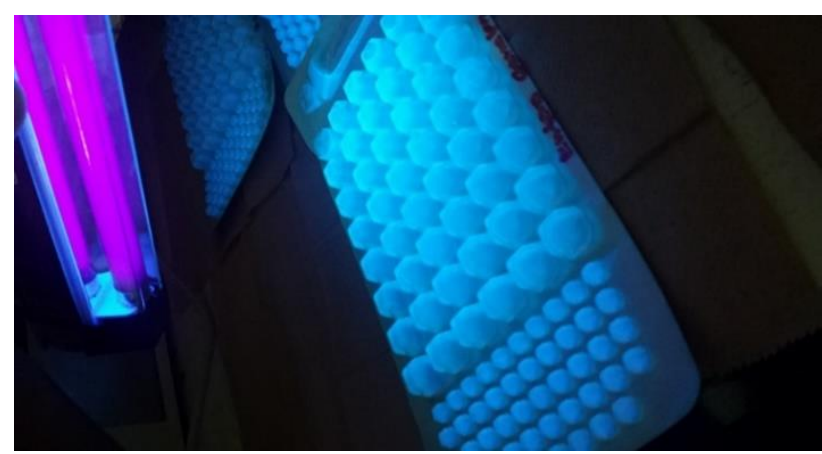

Figura 6 Resultados de la muestra de agua mayo 2017 y octubre 2017, Entero coli, al pasar la lampara de uv en un cuarto obscuro hay presencia de fluorescencia

Fuente: Elaboración propia

La mayoría de los pocillos presentan coloración amarilla, lo que nos indica que tenemos un alto grado de contaminación por coliformes fecales esto se debe a las escorrentías, infiltraciones al manto freático, por la mala disposición de las aguas grises, y de la falta de drenaje.

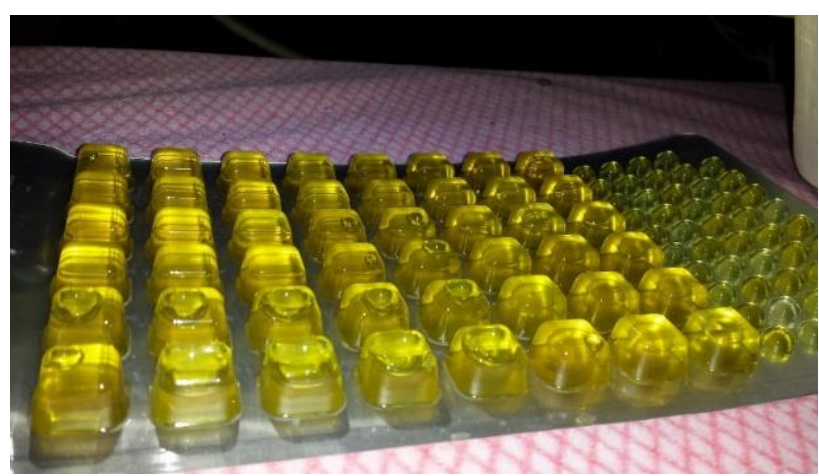

Figura 7 Positivo a Coli Totales en el mes de mayo y octubre 2016-2017, por cambio de coloración amarilla, característica de un alto contenido de microorganismos patógenos presentes en esos meses

El resultado de la fluorescencia en todos los pocillos indica mayor contaminación microbiológica, rebasan el nivel permisible para agua potable que se considera ausencia en el mes de mayo y octubre nos indica la presencia de coliformes fecales en el agua de pozo. De acuerdo con la norma oficial mexicana NOM127-SSA1-1994, Salud Ambiental, modificada en el 2017, véase tabla 4, véase figura 9.

\begin{tabular}{|l|l|}
\hline \multicolumn{1}{|c|}{ Caracteristica } & \multicolumn{1}{c|}{$\begin{array}{c}\text { Limite } \\
\text { permisible }\end{array}$} \\
\hline Organismos coliformes totales & $\begin{array}{l}\text { Ausencia o no } \\
\text { detectables }\end{array}$ \\
\hline $\begin{array}{l}\text { E. coli o coliformes fecales u } \\
\text { organismos termotolerantes }\end{array}$ & $\begin{array}{l}\text { Ausencia o no } \\
\text { detectables }\end{array}$ \\
\hline
\end{tabular}

Tabla 4 Límites permisibles de características microbiológicas Fuente modificación a la norma oficial mexicana NOM-127-SSA1-1994, SALUD AMBIENTAL. Agua para uso y consumo humano

TORRES-RIVERO, Ligia Adelayda. Afectación de la calidad de agua de los pozos del campus Tecnológico de Cancún por mancha urbana. Revista del Desarrollo Urbano y Sustentable. 2020 


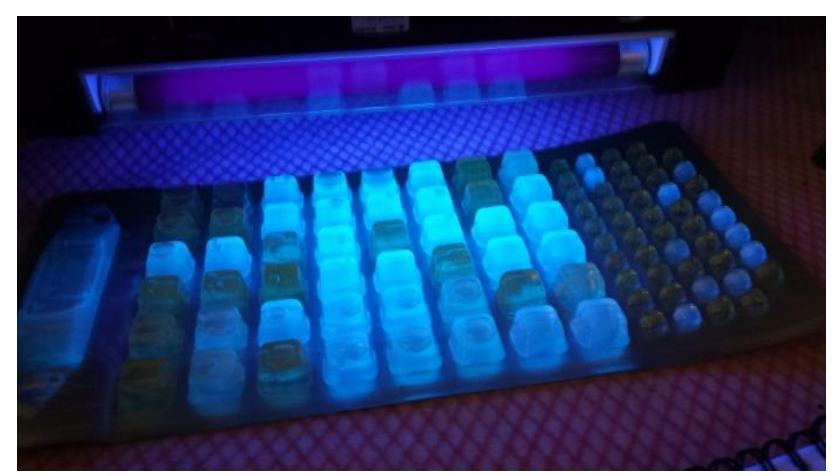

Figura 8 Pozos pequeños 12 positivos y 34 pozos grandes positivos y el grande indicando la presencia de Coli Totales en el mes de mayo y octubre 2016-por cambio de coloración amarilla, a la presencia de fluorescencia, indicando alto contenido de microorganismos patógenos presentes en esos meses, Fuente: Elaboración propia

Para los meses de mayo y octubre del 2017 se siguieron las mismas metodologías encontrando un comportamiento similar al año 2016, presentando una ligera disminución del contenido de microrganismos patógenos E: Coli con respecto a coliformes totales véase figura 8 , como se indica en la siguiente tabla de resultados, vea se tabla 5 . La presencia de $E$. coli en la muestra es factor indicativo de contaminación fecal reciente debida a actividad animal y/o humana en ambientes externos. Esta contaminación también puede deberse a un tratamiento inadecuado de eliminación, de los desechos, dando positivo a Coli Totales en el mes de mayo y octubre 2017, por cambio de coloración amarilla, se nota que el número de pozos que presentan fluorescencia es menor con respecto al año 2016.

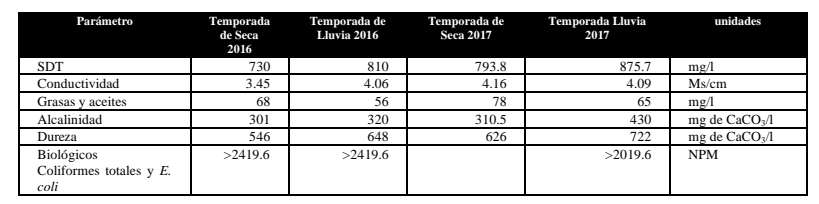

Tabla 5 Resultados obtenidos de acuerdo con las normas vigentes, para análisis de agua comparando los comportamientos de la temporalidad del año 2016 y 2017 y los efectos causados a un cuerpo de agua por el crecimiento poblacional

Fuente: Elaboración propia

\section{Recomendaciones}

Para prevenir la contaminación en los pozos de abastecimiento, se sugiere, por lo que las bacterias detectadas pueden ser eliminadas por este proceso de desinfección. Se deben implementar medidas para desinfectar el agua, con los resultados obtenidos este tipo de agua no son aptas para consumo humano.
Realizar 2 veces al año un monitoreo del recuento de coliformes fecales, cuando es temporada de lluvias las escorrentías acarrean un sinfín de partículas orgánicas como inorgánicas, para el parámetro de grasas y aceites la mala disposición de estos el crecimiento desmedido de cocinas económicas, comidas rápidas, y la falta de cultura para la disposición de los mismos trae como consecuencias la contaminación del manto freático, el resultado nos arroja que están fuera de norma como se indica en la tabla 5.

La dureza, alcalinidad la composición del agua es alta en composición de carbonatos, sulfatos, ocasionando grandes incrustaciones calcáreas en tuberías y obstrucciones de esta, el límite máximo permisible es de $500 \mathrm{mg} / \mathrm{L}$, de acuerdo lo establecido por la NOM-001SEMARNAT-2017.

Solidos disueltos totales. Todos los contaminantes presentes en el agua, a excepción de los gases disueltos, contribuyen a la "carga de sólidos". Los resultados de sólidos pueden ser orgánicos y/o inorgánicos, provenientes de diferentes actividades domésticas, comerciales. El ITCancún está dentro de zona de gran actividad comercial, y de fraccionamientos, por los que presenta un alto contenido de sólidos disueltos. Véase Tabla 5, Gráfico 1.

\begin{tabular}{|l|r|r|r|r|}
\hline Parámetro & Mayo & \multicolumn{1}{|c|}{$\begin{array}{c}\text { Octubre } \\
\text { 2016 }\end{array}$} & \multicolumn{1}{c|}{ Mayo } & \multicolumn{1}{c|}{$\begin{array}{c}\text { Octubre } \\
\text { 2017 }\end{array}$} \\
\hline $\begin{array}{l}\text { Sólidos } \\
\text { Disueltos } \\
\text { (mg/l). }\end{array}$ & 730 & 810 & 793.8 & 875.7 \\
\hline $\begin{array}{l}\text { Sólidos } \\
\text { Suspendidos } \\
\text { (mg/l). }\end{array}$ & 69 & 76 & 60 & 79 \\
\hline $\begin{array}{l}\text { Solitos } \\
\text { Totales } \\
\text { (mg/l). }\end{array}$ & 735 & 790.8 & 795.7 & 793.25 \\
\hline
\end{tabular}

Tabla 6 Resultados del parámetro de solidos el alto contenido en solidos nos indica contaminación por la presencia de materia orgánica

Fuente: Elaboración propia 
Solidos disueltos

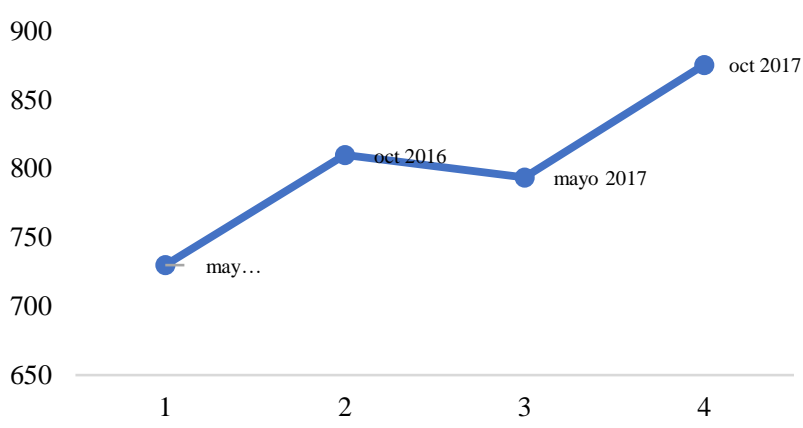

Gráfico 1 Resultados de los sólidos disueltos totales, nos indica que, en el mes de octubre 2017, tiene la una alta carga de contaminantes, ocasionados por filtración al manto por la fragilidad de sus suelos que son escasos, cavernosos por esta zona

Fuente: Elaboración propia

Después de ser evaporado se pesó de nueva manera para calcular con la diferencia de pesos antes y después de ser calentado esto se puede ver en la figura 5. De igual manera se determinó solidos disueltos totales, es este caso se pesó el filtro en el cual se filtró con anterioridad la muestra, este filtro igual se calentó para posteriormente ser pesado, en este caso de igual manera se realizó un cálculo con la diferencia de pesos. La NOM-001SEMARNAT-2017 establece que el límite máximo permisible para agua potable es de $1000 \mathrm{pp}$, por lo que de acuerdo con el grafico no. 1 , los resultados obtenidos se encuentran dentro de lo que establece la norma mexicana.

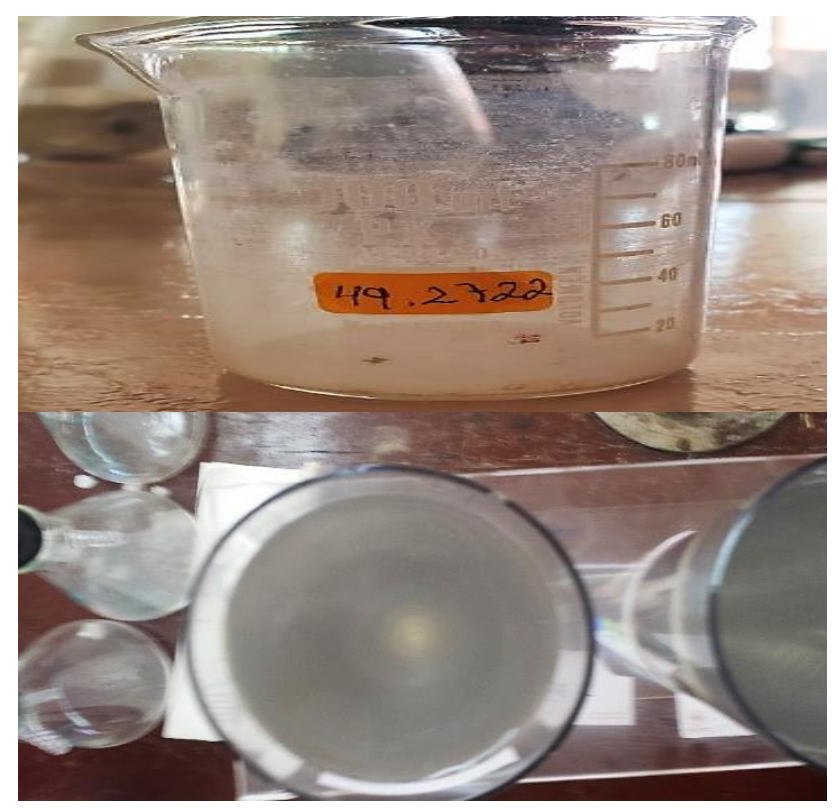

Figura 9 Secado de la muestra y muestra del agua en un cono Imhoff, para la determinación solidos

Fuente: Elaboración propia
Por consiguiente, al tener el cálculo de los sólidos disueltos y suspendidos, se puede realizad de nueva manera otro calculo para los sólidos totales la suma de ambos. Véase gráfico 2.

\section{solidos totales}

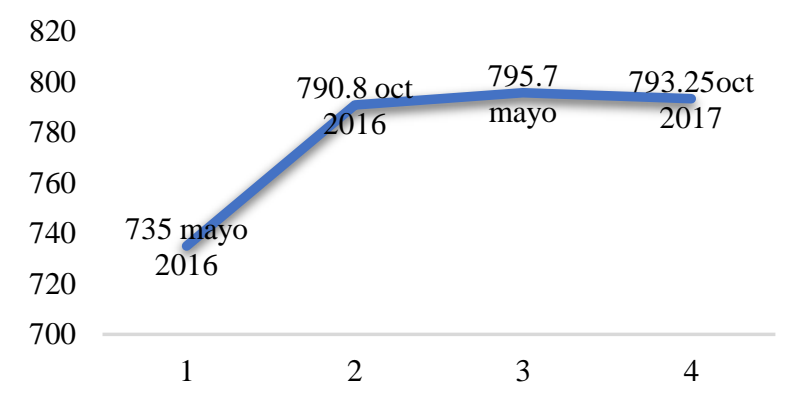

Gráfico 2 Resultados de los sólidos totales, nos indica que en el mes octubre 2016, mayo 2017, de octubre 2017, tiene la una alta concentración de sólidos, ocasionados por filtración al manto por la fragilidad de sus suelos que son escasos por esta zona, o el aumento de la población en la zona, el aumento de comercios, etc.

Fuente: Elaboración propia

Resultados de $\mathrm{pH}$, Conductividad parámetros físicos, en cuanto al $\mathrm{pH}$ se encuentra dentro de lo permisible en la misma se observa claramente la relación existente entre ambos parámetros y además la relación entre sólidos disueltos y conductividad eléctrica, parámetros íntimamente relacionados, véase tabla 7.

\begin{tabular}{|c|c|c|}
\hline $\mathrm{pH}$ mayo & 7.94 & Potenciómetro \\
\hline $\begin{array}{ll}\mathrm{pH} & \text { octubre } \\
& 2016\end{array}$ & 7.9 & Marca: OAKLON \\
\hline pH mayo 2017 & 7.85 & $\begin{array}{c}\text { Modelo: AO- } \\
\text { 35413-00 }\end{array}$ \\
\hline $\begin{array}{ll}\mathrm{pH} & \begin{array}{l}\text { octubre } \\
2017\end{array} \\
\end{array}$ & 7.85 & \\
\hline \multicolumn{3}{|c|}{ Conductividad } \\
\hline C mayo & $140 \mathrm{mV}$ & Potenciómetro \\
\hline C octubre 2016 & $141.4 \mathrm{mV}$ & Marca: OAKLON \\
\hline $\mathrm{C}$ mayo & $121.6 \mathrm{mV}$ & $\begin{array}{r}\text { Modelo: } \quad \text { AO- } \\
\text { 35413-00 }\end{array}$ \\
\hline C octubre 2017 & $141.4 \mathrm{mV}$ & \\
\hline
\end{tabular}

Tabla 7 Resultados de los parámetros físicos de $\mathrm{pH}$, conductividad

Fuente: Elaboración propia

\section{Agradecimiento}

Deseo expresar mi agradecimiento TECNM/Campus ITCancún por el apoyo ha brindado para este trabajo, en el uso del Laboratorio de Aguas y laboratorio de Química. 


\section{Conclusiones}

Al concluir que atendiendo a las características físico-químicas, se confirma el nivel de contaminación de estos cuerpos hídricos. Los resultados de bacterias coliformes totales y fecales obtenidos corrobora el vertimiento de residuales y escorrentías por infiltraciones de las zonas aledañas al pozo, por lo que las aguas de este pozo no son aptas para ser utilizadas como agua potable y es necesario realizar un tratamiento de tipo convencional o especial según el grado de contaminación. Lo que presentan mayor impacto negativo en el pozo y se infiere que el crecimiento poblacional de la zona afecta el agua de pozo, así como las actividades antropomórficas.

\section{Anexos}

\begin{tabular}{|c|c|c|c|c|}
\hline Determinacion & $\begin{array}{c}\text { Material } \\
\text { envase }\end{array}$ & $\begin{array}{l}\begin{array}{l}\text { Volumen minimo } \\
(\mathrm{ml})\end{array} \\
\text {. }\end{array}$ & Preservacion & $\begin{array}{l}\text { Tiempo maximo de } \\
\text { almacenamiento }\end{array}$ \\
\hline Color & $\mathrm{P}, \mathrm{v}$ & 500 & $\begin{array}{l}\text { Refrigerar de } \\
4 \text { a } 10^{\circ} \mathrm{c} \text { y en } \\
\text { la oscuridad }\end{array}$ & 48 horas \\
\hline Dureza total & $\mathrm{P}, \mathrm{v}$ & 100 & $\begin{array}{l}\text { Adicionar } \\
\text { hno3 o h2 } 2504 \\
\text { a ph< } 2\left(2^{*}\right)\end{array}$ & 14 días \\
\hline $\begin{array}{l}\text { Metales en } \\
\text { general }\end{array}$ & $\mathrm{P}, \mathrm{v}(\mathrm{a})$ & 1000 & $\begin{array}{l}\text { Adicionar 1 } \\
\text { ml de ácido } \\
\text { nítrico } \\
\text { concentradop } \\
\text { or cada } 100 \\
\text { ml de } \\
\text { muestra. } \\
\end{array}$ & $\begin{array}{l}180 \text { días } \\
\text { Sólo para la } \\
\text { determinación de } \\
\text { mercurio almacenar } \\
\text { por un máximo de } 4 \\
\text { semanas }\end{array}$ \\
\hline Nitratos & $\mathrm{P}, \mathrm{v}$ & 100 & $\begin{array}{l}\text { Refrigerar de } \\
4 \text { a } 10^{\circ} \mathrm{c} \text { y en } \\
\text { la oscuridad }\end{array}$ & 48 horas \\
\hline Nitritos & $P, v$ & 100 & $\begin{array}{l}\text { Refrigerar de } \\
4 \text { a } 10^{\circ} \mathrm{c} \text { y en } \\
\text { la oscuridad }\end{array}$ & \\
\hline $\begin{array}{l}\text { Nitrógeno } \\
\text { amoniacal }\end{array}$ & $P, v$ & 500 & $\begin{array}{l}\text { Adicionar } \\
\text { h2so4 a ph<2 } \\
\text { y refrigerar } \\
\text { de } 4 \text { a } 10^{\circ} \mathrm{c}\end{array}$ & 7 días \\
\hline$\overline{\text { Olor }}$ & $\mathrm{v}$ & 500 & $\begin{array}{l}\text { Analizar tan } \\
\text { pronto como } \\
\text { sea posible. } \\
\text { Refrigerar }\end{array}$ & 6 hrs. \\
\hline $\mathrm{Ph}$ & $\mathrm{P}, \mathrm{v}$ & 50 & $\begin{array}{l}\text { Analizar } \\
\text { inmediatamen } \\
\text { te }\end{array}$ & \\
\hline Sólidos & $\mathrm{P}, \mathrm{v}$ & 200 & $\begin{array}{l}\text { Refrigerar de } \\
4 \text { a } 10^{\circ} \mathrm{c} \text { y en } \\
\text { la oscuridad }\end{array}$ & 7 días \\
\hline Temperatura & $\mathrm{P}, \mathrm{v}$ & & $\begin{array}{l}\text { Determinar } \\
\text { inmediatamen } \\
\text { te }\end{array}$ & \\
\hline Turbiedad & $\mathrm{P}, \mathrm{v}$ & 100 & $\begin{array}{l}\text { Refrigerar de } \\
4 \text { a } 10^{\circ} \mathrm{c} \text { y en } \\
\text { la oscuridad }\end{array}$ & 24 horas \\
\hline
\end{tabular}

Tabla 8 Preservación de muestras Fuente: Norma oficial mexicana NOM-230-SSA1-2002

\section{Anexo}

\begin{tabular}{|l|r|}
\hline \multicolumn{1}{|c|}{ Caracteristica } & Limite permisible \\
\hline Dureza total (como CaCO3) mg/L & 500,00 \\
\hline Nitratos (como N) & 10,00 \\
\hline Nitritos (como N) & 1,00 \\
\hline Nitrógeno amoniacal (como N) & 0,50 \\
\hline $\begin{array}{l}\mathrm{pH} \text { (potencial de hidrógeno) en } \\
\text { unidades de } \mathrm{pH}\end{array}$ & $6,5-8,5$ \\
\hline Sólidos disueltos totales mg/L & 1000,00 \\
\hline
\end{tabular}

Tabla 9 NOM-127-SSA1-2014, es para el consumo y abastecimiento del agua para su consumo. El contenido de constituyentes químicos deberá ajustarse a lo establecido en los límites se expresan en $\mathrm{mg} / \mathrm{L}$, excepto cuando se indique otra unidad.

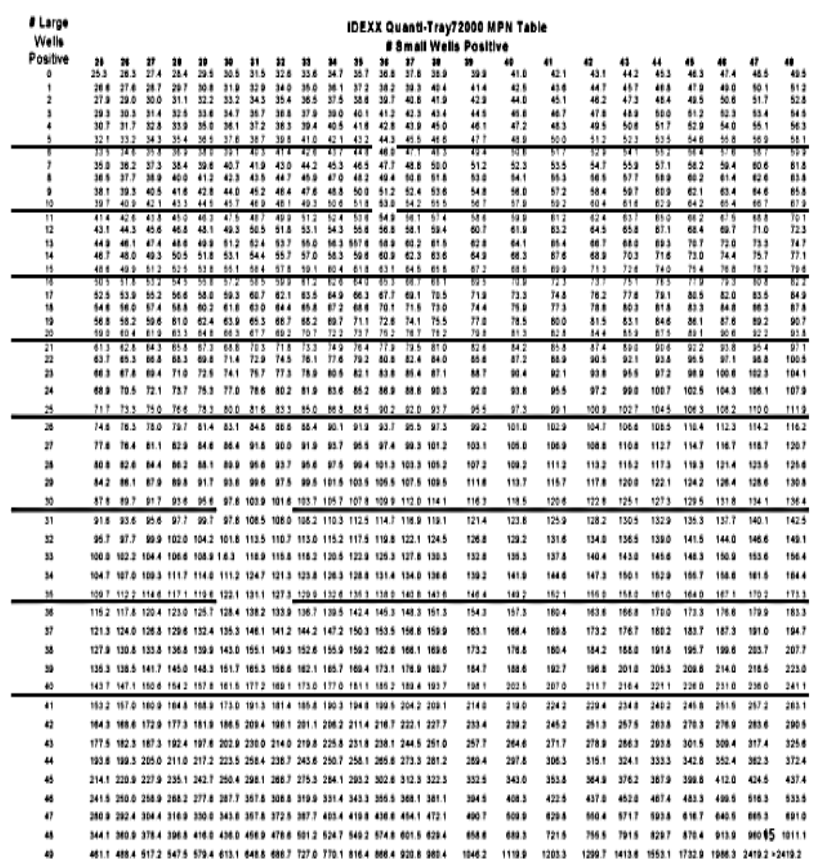

Tabla 10 Identificamos los valores del número más probable por pocillos pequeño o grandes, Tabla IDDeX, por medio de una correlación

Fuente: Elaboración propia, Recuento de los pocillos positivos de E, Coli y Coli

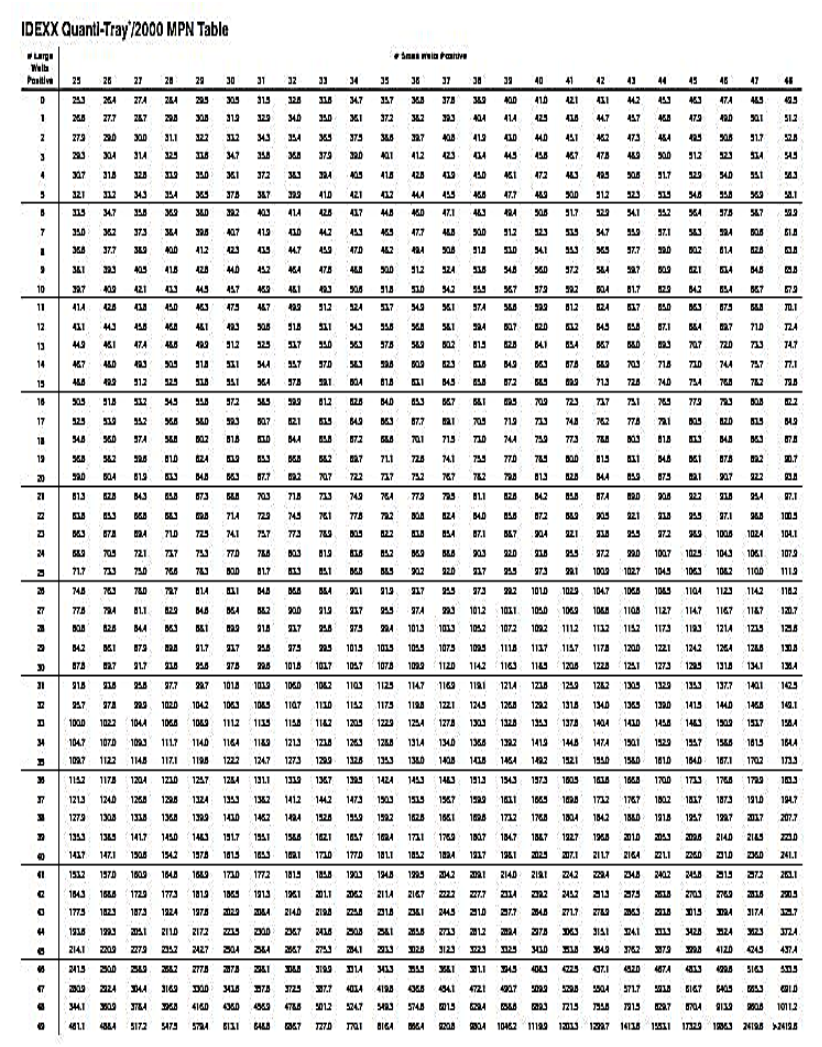

Tabla 11 IDDEX, por medio de una correlació Fuente: Elaboración propia, Recuento de los pocillos positivos de E, Coli y Coli 


\section{Referencias}

Arboleda-Baena, C.M, Arismendi-González, L.M, Sepúlveda-Sánchez, M, Rodríguez-López, M, Betancur-Urán, J. (2016)

Verificación de la metodología colilert para la determinación y cuantificación de coliformes totales y escherichia coli en una matriz de agua natural

Revista Politécnica ISSN 1900-2351 (Impreso), ISSN 2256-5353 (En línea), Año 12, Número 22, páginas 105-112, enero-junio 2016

APHA, AWWA, WPCF. 1998 Standard methods for the examination of water and wastewater. Methods 2340. Washington18th ed Castro, E. G., \& Hita, L. G. (2002). Deterioro de la calidad de agua subterráneapor el desarrollo poblacional: Cancún, Q.Roo. Ingeniería, 6(3), 41-53.

Recuperado el 30 de 4 de 2020 , http://revista.ingenieria.uady.mx/volumen6/dete rioro.pdf

CCPY (Consejo de Cuenca de la Península de Yucatán), 2012, Evaluación de la calidad del agua subterránea en varias localidades de los Municipios de Othón P. Blanco, Bacalar y José María Morelos del Estado de Quintana Roo: Gerencia Regional Península de Yucatán, Informe Final, 122 pp.

Chambi Choque, G. Determinación de Bacterias Coliformes y E. Coli en Agua de consumo Humano del Centro Poblado de Trapiche- Ananea -Puno.[Tesis de grado].Puno-Perú. (Universidad Nacional del Altiplano, 2015 Hem John David

EPA United States Environmental Protection Agency. (2011). National primary drinking water regulations.

Moreno Pareja A, Casallas Jiménez K 2018 Factores ambientales de la gestión del recurso hídrico: un análisis desde el marco normativo contable en Colombia, ciencia.lasalle.edu.co
Medeiros, A.C., Freitas Faial, K.R., Freitas Faial, K.D., da Silva Lopes, I.D., de Oliveira Lima, M., Guimarães, R. M. y Mendonça, N. M., (2017) Quality index of the surface water of Amazonian rivers in industrial areas in Pará, Brazil,

doi: http://doi.org/10.1016/j.marpolbul.2017.09.002, Marine Pollution Bulletin, 123(1-2), 156-164

Gómez-Gutiérrez Anna, Miralles Maria Josepa, Corbella Irene, GarcíaSoledad, NavarroSonia, Llebaria Javier. La calidad sanitaria del agua Delaware consumo

Gaceta Sanitaria, Volume 30, Supplement 1, November 2016, Pages 63-68, Gac Sanit. 2016

http://dx.doi.org/10.1016/j.gaceta.2016.04.0120 213-9111 / C 2016 SESPAS. Publicado por Elsevier Espã n / A, SLU Este es Naciones Unidas Artıculo Abierto Acceso bajo la licencia $\mathrm{CC}$

BY-NC-ND

(http://creativecommons.org/licenses/by-nc-nd / $4.0 /$ )

Misaghi, F., Delgosha, F., Razzaghmanesh, M., y Myers, B. (2017) Introducing a water quality index for assessing water for irrigation purposes: A case study of the Ghezel Ozan River,

doi: http://doi.org/10.1016/j.scitotenv.2017.02.2 26, Science of the Total Environment, 589, 107-116

AnnaGómezGutiérrezMariaJosepaMirallesIrene CorbellaSoledadGarcíaSoniaNavarroJavierLleb ariaAnnaGómezGutiérrezMariaJosepaMirallesI reneCorbellaSoledadGarcíaSoniaNavarroJavier Llebaria

Pérez Jhonny I., Nardini Andrea G. , Galindo Andrés A. (2018) Análisis Comparativo de Índices de Calidad del Agua Aplicados al Río Ranchería, La GuajiraColombia Comparative Analysis of Water Quality Indices Applied to the Ranchería River, La Guajira-Colombia

Fundación CREACUA-Centro Recuperación Ecosistemas Acuáticos, calle $1^{\mathrm{a}} \mathrm{N}^{\circ}$ 1-109, Riohacha, La Guajira-Colombia. versión Online ISSN 0718-0764, Inf. tecnol. vol.29 no.3. http://dx.doi.org/10.4067/0 718-07642018000300047 
Sutadian, A.D., Muttil, N., Yilmaz, A.G., y Perera, B.J.C. (2016) Development of river water quality indices-a review, doi: http://doi.org/10.1007/s10661-015-5050-0, Environ. Monit. Assess. 188, 58.

Velázquez Aguirre Luis 2015 La exploración geohidrológica en México Revista Tecnología y ciencias del agua, (Castro \& Hita, 2002) Páginas 24-29

Instituto Nacional de Estadística y Geografía (México). Anuario estadístico y geográfico de Quintana Roo 2016 / Instituto Nacional de Estadística y Geografía. -- México: INEGI, b 2016. 407 p. ISBN 978-607-739-987-2.

Secretaría del Medio Ambiente y Recursos Naturales (2017). Acuerdo por el que se da a conocer el resultado de los estudios técnicos de aguas nacionales superficiales de la subregión hidrológica Rio Armería de la Región Hidrológica. Armeria, Coahuyana, 16. Recuperado

de: http://www.dof.gob.mx/nota_detalle_popup. php?codigo $=5280549$,

http://www.conabio.gob.mx/conocimiento/regio nalizacion/doctos/rhp_025.htm

Nom-011-CONAGUA (2015)

http://www.dof.gob.mx/nota_detalle.php?codig $\mathrm{o}=5387027 \&$ fecha $=27 / 03 / 2015$

Procedimiento técnico determinación cualitativo y cuantitativa de coliformes totales y escherichia coli en aguas sustrato definido (colilert) AOAC 991.15-1994

Codigo P-SA-63 fecha de emisión 27/10/2015 Versión 01 Página 1 de 26 Nitrato en agua por espectrofotometría ultravioleta Instituto de Hidrología, Meteorología y Estudios Ambientales Ministerio de Ambiente, Vivienda y Desarrollo Territorial - República de Colombia

Subdirección de Hidrología - Grupo Laboratorio de Calidad Ambiental

Código: TP0092 Fecha de elaboración: 29/06/07 Versión: 02 Página 1 de 8 Organización Meteorológica Mundial, 2017 Semarnat, Consulta Técnica

D3_R_AGUA05_01 - SEMARNAT
Gerencia de Calidad del Agua, Junio, 2019. http://dgeiawf.semarnat.gob.mx/

El clima bate varios récords en 2016 que repercuten a escala mundial https://public.wmo.int/es/media/comunicadosde-prensa/el-clima-bate-variosr\%C3\%A9cords-en-2016-que-repercutenescala-mundial 